Original Research Paper

\title{
Pemanfaatan Elektrostimulator AES-5 Sebagai Terapi Komplementer untuk Meningkatkan Imunitas Tubuh di PT. Petro Graha Medika Klinik Satelit Kalimantan Gresik
}

\author{
Nurul Fitriyah $^{1}$, Suryani Dyah Astuti ${ }^{1,2}$, Suhariningsih $^{1}$, Winarno $^{1}$, Reza Destiani ${ }^{1}$ \\ ${ }^{1}$ Proram Studi S1 Fisika, Departemen Fisika, Fakultas Sains dan Teknologi, Universitas Airlangga, Surabaya, Indonesia \\ ${ }^{2}$ Program Magister Teknik Biomedis, Departemen Fisika fakultas Sains dan Teknologi Universitas Airlangga, Surabaya, \\ Indonesia
}

https://doi.org/10.29303/jpmpi.v3i2.1035

Sitasi: Fitriyah, N., Astuti, S. D., Suhariningsih., Winarno \& Destiani, R. (2022). Pemanfaatan Elektrostimulator AES-5 Sebagai Terapi Komplementer untuk Meningkatkan Imunitas Tubuh di PT. Petro Graha Medika Klinik Satelit Kalimantan Gresik. Jurnal Pengabdian Magister Pendidikan IPA, 5(1)

\section{Article history}

Received: 13 Oktober 2021 Revised: 01 Februari 2022

Accepted: 07 Februari 2022

*Corresponding Author: Nurul Fitriyah, Fisika, Universitas Airlangga, Surabaya, Indonesia.

Email:

nurul.fitriyah@fst.unair.ac.id

\begin{abstract}
Kualitas pelayanan kesehatan memiliki peran yang sangat penting dalam peningkatan kualitas kesehatan masyarakat. Permasalahan yang sering dialami oleh tenaga kesehatan (nakes) maupun tenaga kesehatan tradisional (nakestrad) di sebagian besar unit pelayanan kesehatan adalah kurangnya pengetahuan tentang penggunaan alat terapi elektrostimulator AES-5 (Acupuncture Electrostimulator) sebagai alat terapi komplementer untuk meningkatkan imunitas tubuh. Adapun masalah kedua yaitu pemahaman tentang konsep kelistrikan AES-5 dan bagaimana menentukan dosis yang efektif dan aman bagi pasien terapi. Permasalahan tersebut juga dialami oleh mitra pengmas yaitu nakes dan nakestrad mitra yang berasal dari Puskesmas Sukomulyo Kecamatan Manyar Gresik dan di PT. Petro Graha Medika Klinik Satelit Kalimantan, Gresik. Workshop AES-5 sebagai rangkaian kegiatan pengmas telah dilaksanakan secara hybrid (luring terbatas dan daring) dengan peserta kegiatan yaitu nakes dan nakestrad mitra pengmas. Pembekalan materi workshop meliputi konsep dasar kelistrikan elektrotimulator, penentuan dosis efektif dan penggunaan AES-5 secara aman untuk pasien. Hal ini sangat bermanfaat untuk meningkatkan penguasaan konsep dasar kelistrikan pada elektrostimulator dan kemampuan menghitung dosis energi listrik, yang dimiliki oleh nakes dan nakestrad sehingga dapat memberikan pelayanan terapi dengan elektrostimulator AES-5 secara efektif dan aman bagi pasien. Peserta workshop baik nakes dan nakestrad yang mengikuti secara daring dan luring sangat antusias mengikuti seluruh rangkaian acara dan monitoring secara berkala dan keberlanjutan telah dilaksanakan sebagai media komunikasi dua arah dengan mitra PKM untuk mengevaluasi kebermanfaatan AES-5 dan maintenance intrumentasi medis tersebut untuk meningkatkan efektivitas terapi pada pasien.
\end{abstract}

Keywords: Acupuncture Electro-stimulator (AES); Terapi; Health service; Dosis; Instrumentasi medis 


\section{Pendahuluan}

$\mathrm{P}$ erkembangan intrumentasi medis yang sangat cepat selama kurun waktu 5 tahun terkhir tidak luput dari peran masing-masing sektor baik pemerintahan, akademisi, lembaga swasta yang bertindak sebagai mitra dan masyarakat. Badan Pangkalan dan Penerapan Teknologi (BPPT) melalui koordinator bidang teknologi kesehatan telah melakukan kajian terkait permasalahan yang ada di industry intrumentasi medik nasional terutama dari sisi perkembangan teknologi, peluang dan tantangan pasar serta aspek kebijakannya. Instrumentasi medis merupakan perangkat yang dapat digunakan untuk pengukuran besaran biologis atau medis dan memberikan hasil kuantitatif maupun kualitatif. Instrumentasi medis ini berkaitan dengan perangkat medis yakni peralatan yang digunakan dalam pemahaman, penanganan akses, dan pengobatan pada manusia. Urgensi penelitian dan pengembangan industry intrumentasi medis di Indonesia adalah negara indonesia merupakan pasar yang sangat potensial bagi industri peralatan medis. Namun demikian, peluang yang besar ini belum bisa dimanfaatkan oleh industri instrumentasi medis nasional secara optimal karena belum sepenuhnya mampu memproduksi peralatan tersebut. Padahal dari kecenderungan pasar, impor peralatan medis terus mengalami peningkatan yang cukup signifikan dari tahun ke tahun. Tujuan utamanya ini tentunya untuk meningkatkan pelayanan dan kualitas kesehatan masyarakat sekaligus warga negara Indonesia menuju kemandirian industri nasional. Warga negara yang sehat akan meningkatkan indeks kemakmuran negara (Rifatul, 2011).

Acupuncture Electro-stimulator (AES) merupakan alat terapi yang menggunakan energy listrik frekuensi rendah untuk meregenerasi saraf yang rusak agar dapat berfungsi normal kembali (Evrita, dkk., 2017). AES-5 merupakan produk terapi elektrostimulator versi-5 yang telah dikembangkan oleh tim dosen bidang minat Fisika Medis dan Biofisika, Departemen Fisika Universitas Airlangga yang merupakan versi terbaru dari produk sebelumnya. Alat terapi ini dapat dipadukan dengan probe magnetik dan non magnetik untuk memberikan stimulasi energi listrik pada titik akupunktur (meridian) tubuh. Dalam pemberian terapi sangat penting untuk memeperhatikan beberapa aspek antara lain frekuensi, intensitas tegangan output dan lama terapi. Faktor tersebut erat kaitannya dengan dosis terapi. Penggunaan terapi AES-5 dapat dijadikan sebagai pengobatan alternatif yang murah, aman dan pelengkap (komplementer) untuk mengembalikan keseimbangan energi (chi) dalam tubuh. Respon saraf manusia terhadap pemberian rangsangan listrik dengan arus DC menunjukkan adanya kecepatan saraf dalam menghantarkan impuls ketika diberikan tegangan yang bervariasi (Ferry, 2004).

Lebar kurva gelombang AES sebagai fungsi tegangan ouput terhadap waktu memiliki lebar pulsa yang relative kecil untuk mengurangi rasa sakit pasien saat pemeberian rangsangan. Pemberian terapi AES harus disesuaikan dengan kebutuhan dan kondisi pasien. Stimulasi listrik juga dapat diaplikasikan untuk mengurangi rasa sakit saat persalinan (Purnomo, dkk., 2009). Dalam kondisi normal maka frekuensi yang diatur adalah skala normal untuk meningkatkan imunitas tubuh, Begitu pula untuk penguatan energy (tonifikasi) dapat dilakukan dengan frekuensi rendah sedangkan pelemahan neri (sedasi) menggunakan frekuensi tinggi (Indria, 2014). Salah satu optimalisasi frekwensi elktrostimulator adalah pada penderita nyeri punggung bawah dimana hasil menunjukkan penggunaan frekuensi rendah kurang efektif untuk mengurangi rasa nyeri (Djaya, 2011). Hasil ini berkaitan dengan respon saraf pada tubuh yang mengalami nyeri punggung saat diberi terapi AES dimana serabut saraf juga mengirimkan sinyal selain rasa nyeri ke otak (Sumardi, 2014). Pada prinsipnya alat terapi elektrostimulator ini dapat dimanfaatkan sebagai terapi komplementer dan dapat berfungsi optimal jika tenaga kesehatan sebagai pengguna alat terapi ini dapat menggunakannya dengan cara benar dengan dosis yang tepat.

Departemen Fisika Universitas Airlangga yang dipelopori oleh Tim Peneliti yang terdiri dari dosen dan mahasiswa di Laboratorium Biofisika dan Fisika Medis melakukan penelitian secara intensif untuk mnyelesaikan masalah diatas. Penelitian yang dimaksud adalah menghasilkan produk instrumen medis yang bersifat pocket size, portable, untuk kebutuhan preventif, serta tingkat konektivitas yang lebih mudah. Selanjutnya produk ini digunakan untuk pelatihan bagi praktisi di Puskesmas dan Rumah Sakit. 
Berdasarkan analisis permasalahan dan situasi diatas, melalui pelaksanaan workshop AES5 kepada para nakes dan nakestrad dalam serangkaian kegiatan Program Kemitraan Masyarakat (PKM), pengetahuan dan kemampuan peserta PKM tentang konsep kelistrikan AES-5 dan cara penggunaannya dapat ditingkatkan sehingga kualitas pelayanan kesehatan melalui pemeberian terapi tersebut dapat dimaksimalkan untuk meningkatkan kesejahteraan masyarakat.

\section{Metode}

Pengabdian kepada mayarakat ini bermitra dengan nakes dan nakestrad dari unit pelayanan kesehatan di Kabupaten Gresik Jawa Timur yaitu Puskesmas Sukomulyo dan PT. Petro Graha Medika Klinik Satelit Kalimantan. Kegiatan ini dilaksanakan secara hybrid dimana luring terbatas dilaksanakan di aula pertemuan PT. Petro Graha Medika Klinik Satelit Kalimantan sekaligus disiarkan dan diikuti secara online via zoom dan live streaming Youtube pada tanggal 31 Agustus 2021.

Rangkaian kegiatan pengmas ini antara lain Workshop AES-5 yang bertajuk " Pemanfaatan Elektrostimulator AES-5 sebagai Terapi Komplementer untuk Meningkatkan Imunitas Tubuh" dan pemberian hibah AES-5 serta bahan medis kepada mitra PKM. Workhsop AES-5 meliputi pembekalan materi tentang konsep kelistrikan AES-5 dan metode kalkulasi dosis efektif terapi yang disampaikan oleh dosen Fisika Universitas Airlangga. Disamping itu tata cara penggunaan AES-5 dengan benar juga diajarkan selama workshop dengan harapan nakes dan nakestrad dapat memberikan alternative terapi untuk masyarakat dengan menggunakan AES-5 yang aman dan murah. Setelah sesi workshop, penulis selaku panitia kegiatan pengmas memberikan hibah AES-5 untuk masing-masing mitra PKM dan juga hibah bahan medis. Adapun bahan- bahan penunjang medis tersebut antara lain masker bedah, masker KN-95, APD full hazmat, APD standart, latex glove, sarung tangan latex tebal, tisu, kacamata (google), thermogun , face shield, liquid hand sanitizer, gel hand sanitizer dan lain-lain.

Elektrostimulator AES-4 merupakah salah satu produk instrument medis yang dihasilkan oleh tim peneliti dan dosen KBK Biofisika dan Fisika
Medis. Elektrostimulator AES-4 ini dapat dimanfaatkan sebagai alat terapi komplementer yang digunakan dengan pemberian rangsanagan tegangan listrik pada titik - titik meridian akupunktur.

Pemahaman tentang konsep kelistrikan AES-5 meliputi bagaimana menentuaka tegangan efektif Veff elektrostimulator saat terapi. Sumber energi listrik AES-5 adalah arus PLN (AC). Tegangan listrik bolak balik memiliki tegangan maksimum atau tegangan puncak (peak) $\mathrm{V}_{\mathrm{p}}$, tegangan puncak-ke-puncak (peak-to-peak) $\mathrm{V}_{\mathrm{pp}}$, tegangan rata-rata (average) $\square \mathrm{V}$ dan tegangan akar kuadrat rata-rata (root-mean squares) $\mathrm{V}_{\mathrm{rms}}$. Besar tegangan listrik ini bergantung pada bentuk fungsi tegangannya.

Berdasarkan analisis tegangan pada gelombang spike (bentuk gelombang) elektrostimulator, adapun pembahasan terkait penentuan $V_{\text {eff }}$ yang merupakan besaran yang penting. Tegangan spike dengan lebar dasar $\square \mathrm{t}$ ditunjukkan oleh Gambar 1(a). Bentuk persamaan tegangan anntara $\mathrm{t}=0$ sampai $\mathrm{t}=\mathrm{T}$ adalah seperti berikut.

$$
\begin{aligned}
& \mathrm{V}_{\mathrm{D}}(\mathrm{t})=-\left[\mathrm{V}_{\mathrm{p}} / \Delta \mathrm{t}\right] \mathrm{t}+\mathrm{V}_{\mathrm{p}} \text { untuk } 0<\mathrm{t}<\mathrm{t}_{1} \\
& =0 \quad \text { untuk } \mathrm{t}_{1}<\mathrm{t}<\mathrm{T}
\end{aligned}
$$

Besaran $\mathrm{V}_{\text {eff }}$ signal tegangan spike ditentukan seperti uraian berikut.

$$
\mathrm{V}_{\mathrm{eff}}^{2}=\frac{\int_{0}^{T}\left\{V_{D}(\mathrm{t})\right\}^{2}}{\int_{0}^{T} \mathrm{dt}}
$$

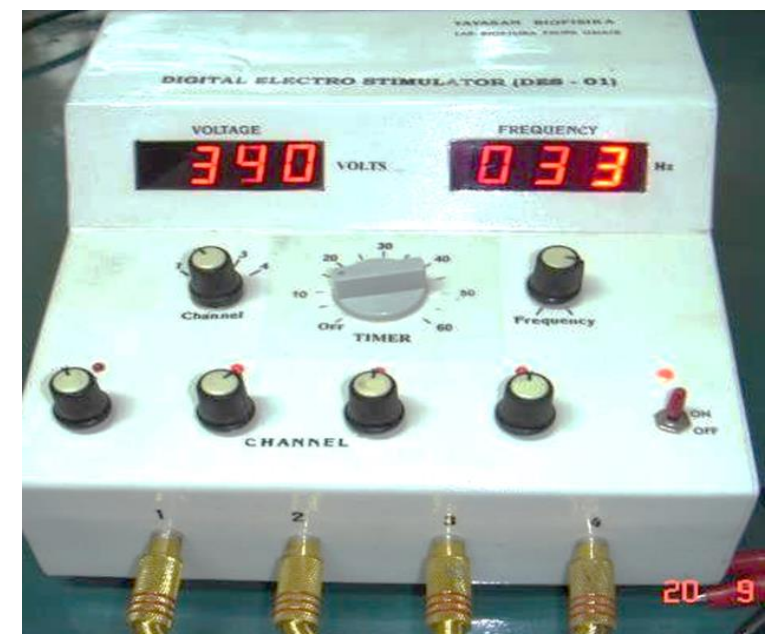



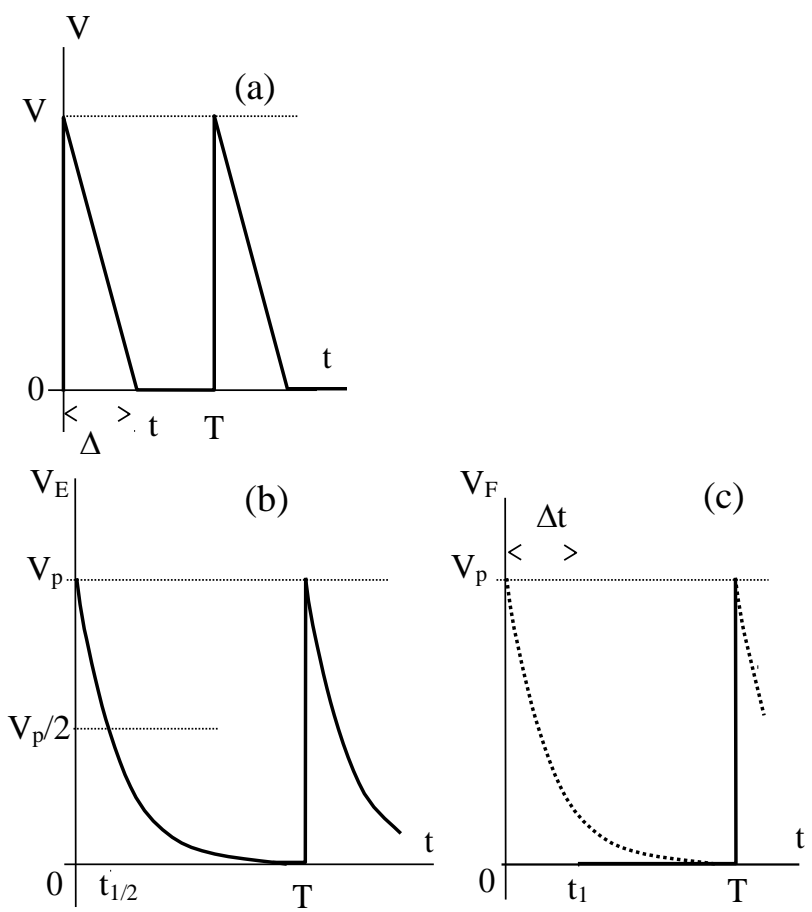

Gambar 1 (a) Grafik tegangan spike, (b) Grafik tegangan eksponensial, (c) Pendekatan grafik eksponensial dengan spike

Persamaan (2) akan menjadi:

$\mathrm{V}_{\text {eff }}^{2}=\frac{\mathrm{Vp}}{\sqrt{3}} \sqrt{\frac{\Delta t}{T}}$

Untuk $\Delta \mathrm{t}=\mathrm{T}$ membentuk tegangan gigi-gergaji dengan $\mathrm{V}_{\text {eff }}=\mathrm{V}_{\mathrm{p}} / \sqrt{3}$.

Berdasarkan persamaan matematik untuk tegangan eksponesial (Gambar 1 (b)) satu periode $\mathrm{T}$ diperoleh tegangan $\mathrm{v}(\mathrm{t})$ akan menurun secara eksponensial dan akan sama dengan nol pada $\mathrm{t}=\mathrm{T}$. Waktu yang diperlukan sejak $\mathrm{t}=0$ sampai tegangan menjadi setengah kali semula disebut waktu paruh dengan lambang $\mathrm{t} 1 / 2$. Sehingga $\mathrm{V}_{\text {eff }}$ untuk tegangan eksponensial menjadi:

$$
\begin{aligned}
& \text { Veff }=k \mathrm{Vp} \\
& k=\frac{1}{1.177} \sqrt{\frac{1 / 2}{t}}
\end{aligned}
$$

dengan $k$ adalah konstanta tegangan efektif, T adalah periode tegangan eksponential (Suhariningsih, dkk. 2020). Besaran Vp untuk tegangan persegi sama dengan $1 / 2$ kali tegangan puncak-ke-puncak Vpp. Untuk chanel yang sama pada suatu stimulator akan memberikan nilai t1/2 yang sama. Adapun diagram blok pengukuran tegangan output elektrostimulator dan penggunaannya saat terapi ditunjukkan pada Gambar 2

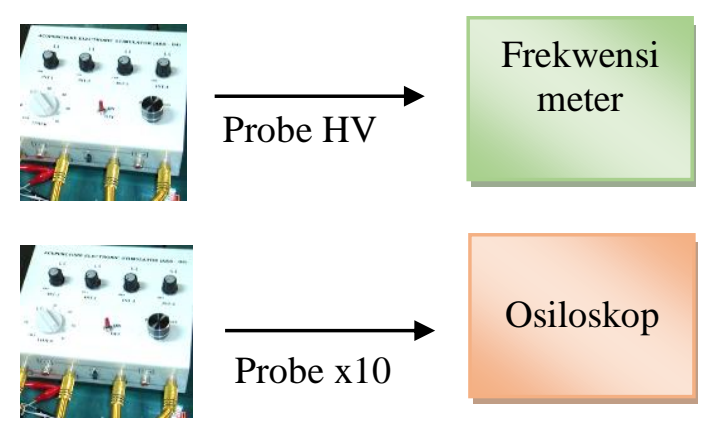

(a)

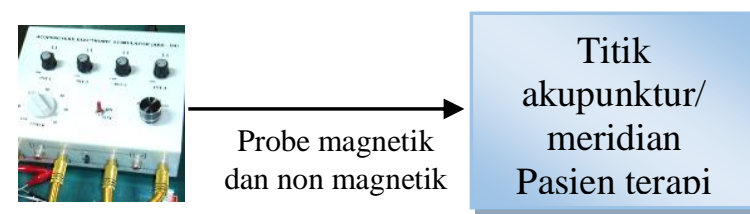

(b)

Gambar 2 (a) Diagram blok pengukuran tegangan output AES (seri 4) dengan frekwensimeter dan osiloskop, (b) diagram blok penggunaan AES-5 saat terapi

Tegangan output AES-5 yang terukur oleh frekwensimeter akan memiliki 3 skala frekuensi yaitu phuw, normal dan shiek. Frekuensi phuw adalah frekuensi rendah yang dipakai untuk applikasi penguatan energy dalam tubuh (tonifikasi). Sedangkan skala normal untuk applikasi penyegaran tubuh seperti menjaga imunitas tubuh. Frekuensi shiek merupakan frekuensi tinggi yang digunakan untuk pelemahan energi yang berlebihan di dalam tubuh (sedasi). Jika pemberian frekeunsi sangat tinggi melebihi ambang batas dapat memebrikan efek anestesi kepada pasien.

Pada sesi akhir kegiatan pengabdian kepada masyarakat ini peserta diberikan form kuisioner kepuasan pelaksanaan yang berisi evaluasi/ feedback dari para nakes dan nakestrad selaku peserta workshop AES-5. Koordinator mitra yang diwakilkan oleh beberpa nakes dan nakestrad yang menghadiri acara secara luring terbatas juga diberikan kesempatan untuk menyampaikan pesan 
dan kesannya selama mengikuti workshop AES-5 ini.

\section{Hasil dan Pembahasan}

Kegiatan program kemitraan masyarakat (PKM) tahun 2021 yang diselenggarakan oleh Departemen Fisika Universitas Airlangga mengusung tema di bidang health service yang berjudul "Pemanfaatan AES-5 sebagai terapi Komplementer untuk Meningkatkan Imunitas Tubuh". Kegiatan ini dikemas dalam sebuah workshop AES-5 yang dilakukan secara hybrid (luring terbatas dan daring) karena kondisi pandemi yang belum memungkinkan dilaksanakannya secara luring. Workshop AES-5 dilaksanakan pada tanggal 31 Agustus 2021 di Aula pertemuan PT. Petro Graha Medika Klinik Satelit Kalimantan Gresik dan dihadiri oleh mitra PKM yang terdiri dari nakes (dokter, perawat, bidan) dan nakestrad (akupunkturis, ahli batra) dari unit pelayan kesehatan Kabupaten Gresik. Adapun mitra PKM adalah Puskesmas Sukomulyo dan PT. Petro Graha Medika Klinik Satelit Kalimantan Gresik. Sehari sebelum pelaksanaan kegiatan pengmas luring seluruh panitia wajib melakukan swab antigen dengan hasil negatif sebagai upaya menaati protokal kesehatan selama pandemi.

Workhsop AES-5 yang dibuka saat luring terbatas juga diikuti secara online melalui zoom oleh nakes/nakestrad, dosen Fisika Unair, mahasiswa, alumni dan tenaga kependidikan yang tidak dapat menghadiri kegiatan offline. Kegiatan online ini juga disiarkan dan live streaming di kanal YouTube. Acara dibuka oleh MC (master of ceremony) Osmalina Nur Rahma, S.T., M.Si dan dilanjutkan dengan pembacaan doa oleh mahasiswa S2 Teknik Biomedis Universitas Airlangga. Selanjutnya acara dibuka secara resmi oleh Dekan Fakultas Sains dan Teknologi Universits Airlangga Prof. Dr. Moh. Yasin, M.Si. dan diikuti sambutan dari ketua pelaksana kegiatan pengmas Nurul Fitriyah, S.Si., M.Sc. Sambutan berikutnya disampaikan oleh koordinator mitra PKM yaitu dr. Puspita dari Puskesmas Sukomulyo Gresik (Gambar 3) dan dr. Edwin direktur manajement Klinik Satelit Kalimantan.

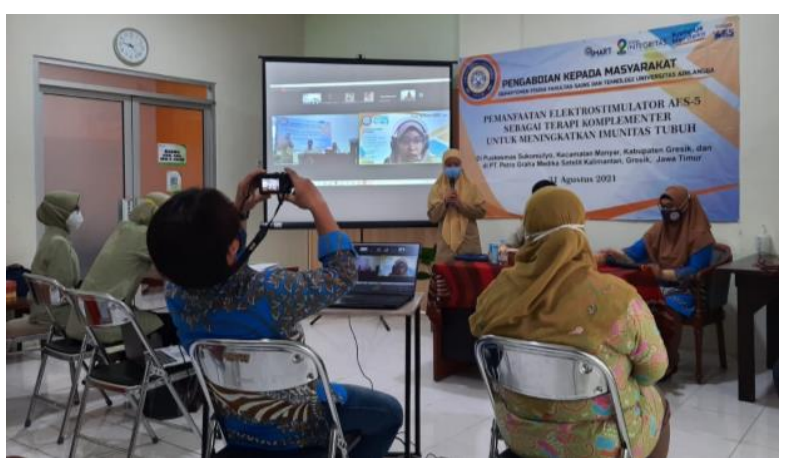

Gambar 3. Sambutan dari koordinator mitra PKM dr. Puspita dari Puskesmas Sukomulyo Gresik

Pemberian materi sesi pertama Workshop disampaikan oleh narasumber yang merupakan dosen Fisika Unair Prof. Dr. Suhariningsih dengan topik konsep kelistrikan AES-5 kepada peserta kegiatan. Konsep kelistrikan meliputi prinsip kerja AES-5 sebagai alat terapi komplementer, pengukuran tegangan $\left(\mathrm{V}_{\text {eff }}\right)$ output elektrostimulaor dan bagaimana menghitung dosis efektif. Dengan pembekalan ini diharapkan nakes/nakestrad dapat menggunakan AES-5 secara optimal saat memeberikan pelayannan terapi untuk masyarakat. Sesi kedua workshop diisi dengan peragaan uji coba penggunaan AES-5 langsung oleh nakes/nakestrad yang disampaiakn oleh Prof. Dr. Suryani Dyah Astuti dan dipandu oleh moderator Winarno, S.T., M.T selaku dosen Fisika Unair selama kegiatan workshop dan sesi diskusi interaktif baik secara langsung dengan peserta luring terbatas maupun dengan peserta pengmas yang mengikuti secara daring. Beberpa foto dokumentasi pelaksanaan workshop AES-5 dapat dilihat pada Gambar 4 di bawah ini.

Nakes dan nakestrad tampak sangat antusias mengikuti workshop yang dapat terlihat dari video dokumentasi saat luring dimana saat praktek ujicoba AES-5 secara langsung nakes yang menjadi testi uji coba sangat memperhatikan penejlasan yang disampaiakn oleh para nara sumber. Diskusi interaktif juga berjalan dengan sangat baik dengan beberpa pertanyaan yang disampaikan oleh peserta pengmas yang mengikuti kegiatan baik secara luring maupun daring. 

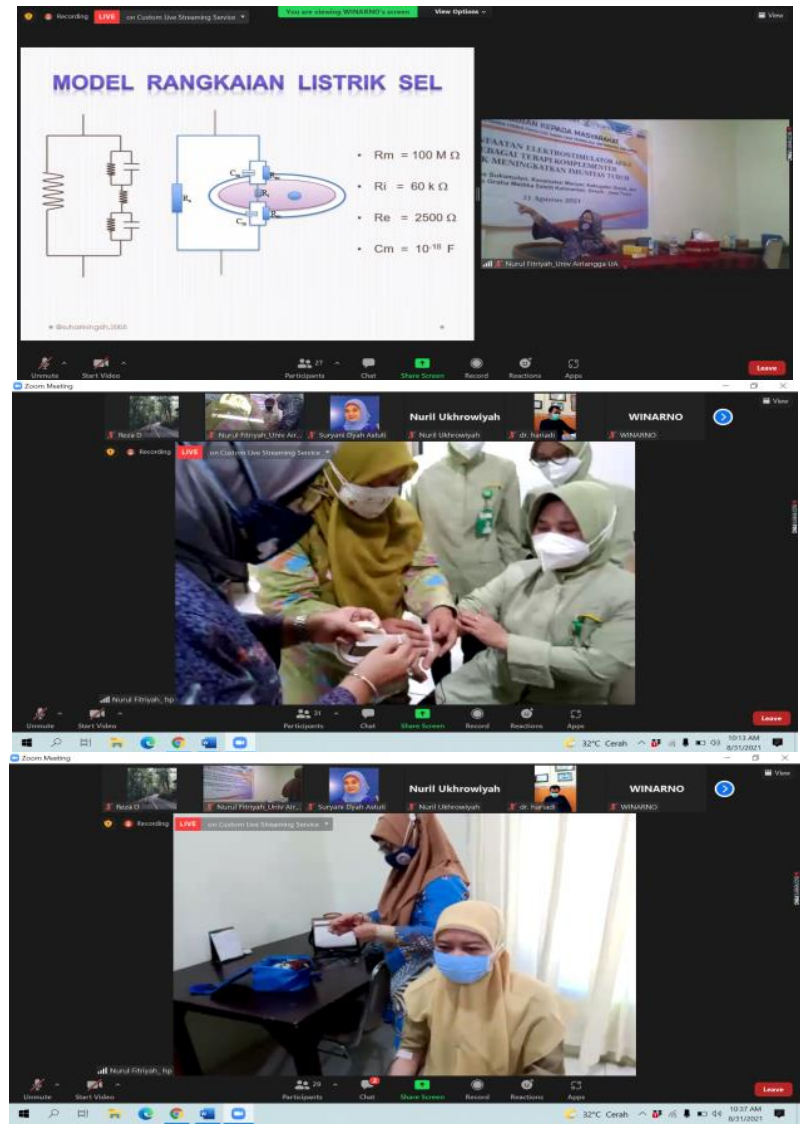

Gambar 4. Pelaksanaan Workshop AES-5 secara hybrid

Sesi terkhir dari kegiatan ini ditutup dengan penyerahan hibah berupa 1 unit AES-5 dan hibah bantuan bahan penunjang medis dari panitia kegiatan kepada masing-masing mitra PKM. AES-5 yang diberikan sudah dilengkapi dengan probelelectrode magnetik dan magnetic serta kabel penghubung dan petunjuk dasar penggunaannya. Adapun bahan- bahan penunjang medis yang dihibahkan antara lain masker bedah, masker KN95. APD full hazmat, APD standart, latex glove, sarung tangan latex tebal, tisu, kacamata (google), thermogun, face shield, liquid hand sanitizer, gel hand sanitizer dan lain-lain. Proses penyerahan hibah AES-5 dan bahan penunjang medis diserahkan secara simbolis oleh Deapartemen Fisika Unair yang diwakilkan kepada Prof. Dr. Suhariningsih, Prof. Dr. Suryani Dyah Astuti dan Nurul Fitriyah, S.Si., M.Sc. Penyerahan hibah AES-5 dan hibah bahan penunjang medis dapat dilihat pada Gambar 5.
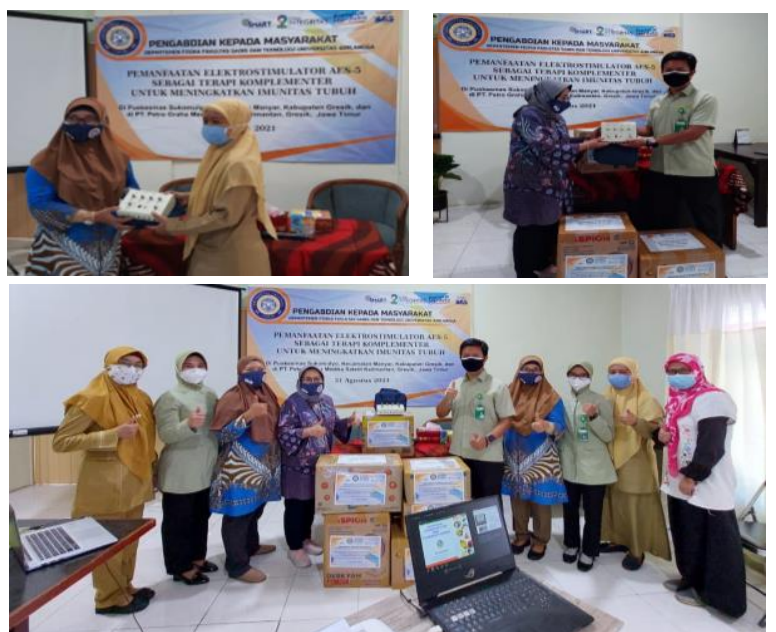

Gambar 5. Penyerahan hibah AES-5 dan bahan penunjang medis kepada mitra PKM

Evaluasi kegiatan ini dilakukan dengan pemberian form kuisioner kepada seluruh peserta baik yang mengikuti secara luring maupun daring. Hal ini dilakukan untuk perbaikan pelayanan dan pelaksanaan kegiatan pengmas di masa yang akan datang sehingga kebermanfaatan kegiatan ini dapat dirasakan semakin luas dengan pelaksanaan yang optimal. Komponen evaluasi dibagi menjadi 4 bagian antara lain kualitas materi dan narasumber, manajemen dan organisasi kegiatan, fasilitas selama kegiatan pengmas dan dukunagan unit kerja terhadap pelaksanaan kegiatan pengmas.

Adapun hasil rekapitulasi prosentase nilai kuisioner seperti pada Tabel 1. Indeks skala kepuasan dibuat dari skala 1-4 dengan keterangan kategori indeks skala:

$$
\begin{aligned}
& 1=\text { sangat memuaskan } \\
& 2=\text { memuaskan } \\
& 3=\text { tidak memuaskan } \\
& 4=\text { sangat tidak memuaskan }
\end{aligned}
$$

Tabel 1 Hasil Rekapitulasi Prosentase Nilai Kuisioner Peserta Workshop AES-5

\begin{tabular}{llc}
\hline No. & \multicolumn{1}{c}{ Komponen Evaluasi } & $\begin{array}{c}\text { (Skala)/Skor } \\
(\mathbf{\%})\end{array}$ \\
\hline \multirow{3}{*}{$\begin{array}{l}\text { I. Kualitas Materi dan Nara } \\
\text { Sumber }\end{array}$} & \\
Kemutakhiran Materi yang & $(4): 91 \% ;$ \\
& disajikan & $(3): 9 \%$ \\
2 & Kemanfaatan Materi yang & $(4): 92 \% ;$ \\
diberikan & $(3): 8 \%$ \\
3 & Kualitas Penyampaian Materi & $(4): 90 \% ;$ \\
& II. Manajemen dan Organisasi & $(3): 10 \%$ \\
\hline
\end{tabular}




\begin{tabular}{|c|c|c|}
\hline No. & Komponen Evaluasi & $\begin{array}{c}\text { (Skala)/Skor } \\
(\%)\end{array}$ \\
\hline & Kegiatan & \\
\hline 4 & $\begin{array}{l}\text { Pemilihan Waktu (hari, tanggal, } \\
\text { dan jam) kegiatan yang tepat }\end{array}$ & $\begin{array}{l}\text { (4): } 85 \% \text {; } \\
\text { (3): } 14 \% \text {; } \\
\text { (2): } 1 \%\end{array}$ \\
\hline 5 & $\begin{array}{l}\text { Publikasi/Undangan Kegiatan } \\
\text { Yang Memadai }\end{array}$ & $\begin{array}{l}\text { (4): } 88 \% \text {; } \\
\text { (3): } 12 \%\end{array}$ \\
\hline 6 & $\begin{array}{l}\text { Pengaturan Waktu dan Acara } \\
\text { Selama Kegiatan }\end{array}$ & $\begin{array}{l}\text { (4): } 89 \% \text {; } \\
\text { (3): } 11 \%\end{array}$ \\
\hline 7 & $\begin{array}{l}\text { Kemudahan Memperoleh } \\
\text { Informasi Dari Panitia }\end{array}$ & $\begin{array}{l}\text { (4): } 89 \% \text {; } \\
\text { (3): } 11 \%\end{array}$ \\
\hline 8 & $\begin{array}{l}\text { Kualitas Layanan Panitia Selama } \\
\text { Kegiatan Pengmas }\end{array}$ & $\begin{array}{l}\text { (4): } 94 \% \text {; } \\
\text { (3): } 6 \%\end{array}$ \\
\hline & $\begin{array}{l}\text { III. Fasilitas Selama Kegiatan } \\
\text { Pengmas }\end{array}$ & \\
\hline 9 & $\begin{array}{l}\text { Ketersediaan Fasilitas Pendukung } \\
\text { Selama Kegiatan Berlangsung } \\
\text { Ketersediaan Fasilitas Media }\end{array}$ & $\begin{array}{l}\text { (4): } 96 \% \text {; } \\
\text { (3): } 4 \%\end{array}$ \\
\hline 10 & $\begin{array}{l}\text { Pembelajaran (LCD, Komputer, } \\
\text { Peraga, Peralatan Praktikum, } \\
\text { dsb.) }\end{array}$ & $\begin{array}{l}\text { (4): } 93 \% \text {; } \\
\text { (3): } 7 \%\end{array}$ \\
\hline & $\begin{array}{l}\text { IV. Dukungan Unit } \\
\text { KerjaTerhadap Pelaksanaan } \\
\text { Kegiatan Pengmas }\end{array}$ & \\
\hline 11 & $\begin{array}{l}\text { Puskesmas di lokasi saudara } \\
\text { mendukung kegiatan ini }\end{array}$ & $\begin{array}{l}\text { (4): } 95 \% \text {; } \\
\text { (3): } 5 \%\end{array}$ \\
\hline 12 & $\begin{array}{l}\text { Nakes dan kader di lokasi saudara } \\
\text { mendukung kegiatan ini }\end{array}$ & $\begin{array}{l}\text { (4): } 93 \% \text {; } \\
\text { (3): } 7 \%\end{array}$ \\
\hline
\end{tabular}

Berdasarkan Tabel 1, dapat dianalisa bahwa sebagian besar nakes dan nakestrad pserta workshop memeberikan skala 1 yang berarti sangat memuaskan dan skala 2 sebagai ekspersi memuaskan. Untuk keseluruhan komponen evaluasi yang meliputi kualitas materi dan narasumber, managemen dan organisasi acara, fasilitas selama kegiatan dan dukungan unit kerja terhadap pelaksanaan kegiatan pengabdian masyarakat, dapat diambil rata-rata indeks kepuasan peserta sangat baik. Hasil diatas akan dijadikan sebagai acuan evaluasi untuk pelaksanaan kegiatan pengmas di masa yang akan datang agar lebih baik lagi. Adapun beberpa pesan dan kesan yang disampaiakan peserta workshop menyatakan bahwa kegiatan ini sangat menarik dan sangat bermanfaat, banyak wawasan yang diperoleh dan sebagian besar ungkapan terima kasih kepada panitia pengmas yang telah menyelenggarakan acara seccara hybrid.

Sehingga dapat disimpulkan bahwa berdasarkan analisa hasil kuisioner secara general pelaksanaan kegiatan pengabdian kepada masyarakat ini berjalan dengan sukses, lancar, sangat memuaskan dan semoga memberikan kebermanfaatan bagi mitra PKM secara khususnya dan masyarakat Gresik pada umumnya. Semoga kedepannya kegiatan ini dapat dilaksanakan secara kontinyu dan berkesinambungan serta terstruktur dengan lebih baik lagi.

\section{Kesimpulan}

Kegiatan pengabdian kepada masyarakat yang bertajuk pemanfaatan AES-5 sebagai terapi komplementer untuk meningkatkan imunitas tubuh di PT. Petro Graha Medika Klinik Satelit Kalimantan pada tanggal 31 Agustus 2021 berjalan dengan lancar dan sangat baik. Pelaksanaan dilaksanakan secara hybrid dimana pembekalan materi konsep kelistrikan AES-5 dan tata cara penggunaannya dikemas dalam acara Workshop AES-5 yang diikuti secara luring terbatas oleh para nakes dan nakestrad dari mitra PKM yaitu Puskesmas Sukomulyo dan Klinik Satelit Kalimantan. Workhsop tersebut juga disiarkan secara live streaming via zoom dan Youtube bagi para peserta lainnya yang terdiri dari nakes/nakestrad mitra, dosen, mahasiswa, alumni dan fiskawan medis yang tidak dapat mengikuti kegiatan secara luring. Seluruh peserta sangat antusias dan berdasarkan survey kepuasan peserta workshop menunjukkan prosentase kepuasaan diatas 95\%. Nakes dan nakestrad mitra PKM yang mengikuti acara luring terbatas juga diberikan hibah bantuan medis yang terdiri dari APD, masker medis, kacamata /googlge, sarung tangan, thermogun dan lain-lain sebagai penunjang untuk peningkatan pelayanan kesehatan dan perlindungan diri para nakes selama masa pandemi.

\section{Saran}

Saran untuk pelaksanaan kegiatan pengabdian kepada masyarakat yang akan datang adalah pelaksanaannya diadakan full luring jika kondisi pandemi telah berakhir/ terkendali agar workshop AES-5 dapat diiikuti oleh nakes/nakestrad dalam skala yang lebih besar.

\section{Ucapan Terima Kasih}

Penulis mengucapkan terima kasih kepada Fakultas Sains dan Teknologi Universitas Airlangga yang telah membiayai pelaksanaan pelaksanaan kegiatan pengabdian masyarakat ini 
dengan Dana Rencana Kegiatan Anggaran Tahunan (RKAT) Tahun 2021 dengan Nomor 3087/UN3.1.8/PM/2021 Tanggal 7 Mei 2021.

\section{Daftar Pustaka}

Djaya, H. P, 2011. Transcutaneous Electrical Nerve Stimulation. Fakultas Teknik Universitas Hasanuddin.

Evrita, L. U., Irawadi B., I Made G. G. P., 2017. Simulasi Alat Elektrostimulator Akupunktur Berbasis Mikrokontroler ATMega16. Teknoin Vol. 23 No. 1 hal. 29-42

Ferry, 2004. Pengukuran Impuls tegangan pada Saraf Sensorik Manusia dengan Memberikan rangsangan Listrik serta Pemodelannya dalam Rangkaian Impedansi. Universitas Gajah mada, Yogyakarta.

Indria, D. P. 2014. Perancangan Alat Pilse Oximetry dengan Sistem Alarm Prioritas sebagai Vital Monitoring Terhadap Pasien. Universitas Respati Yogyakarta.

Rifatul, W., (2011). Urgensi Berkembangnya Industri Instrumentasi Medik di Indonesia Menuju Kemandirian Industri Mendik Nasional. https://www.bppt.go.id/beritabppt/urgensi-berkembangnya-industriinstrumentasi-medik-di-indonesiamenuju-kemandirian-industri-nasional diakses pada tanggal 12 Maret 2021.

Purnomo, W., Moersintowarti B. N., Rita, Y. 2009. Penggunaan Stimuli Transcutaneous Electrical Nerve Stimulation (Tens) Dapat Menurunkan Intensitas Nyeri dan Tingkat Kecemasan pada Persalinan Kala I. Indonesian Journal of Public Health, vol. 5 , no. 3.

Suhariningsih, Astuti, S. D., Tri, A. P., Fitriyah, N., 2020. Buku Petunjuk Praktikum Fisika Eksperimental I. Universitas Airlangga Publishing, edisi 2020 hal. 22-27

Sumardi, J., I Nyoman, G. 2014. Perencanaan dan pembuatan Alat Transcutaneous Electrical Nerve Stimulation (TENS) Berbasis Microcontroller Atmega. Akademi Teknik Elektro Semarang. Semarang. 